\title{
Dentist laboratory communication
}

Sabah A Ismail

BDS, MSc (Lect)

Abdul-Haq A Suliman BDS, MS, MS, PhD (Prof)

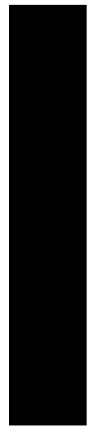

\section{ABSTRACT}

The aim of this study was to evaluate the common errors that may occur during crown and bridge construction. Four hundred stone models were used in this study for fabrication of 265 bridges and 135 single crown. The total number of units was 1141. Four main parameters were evaluated for each stone model: General informa-tion about the case, the condition of the stone model, the type of impression mater-ial and the prepared abutment tooth.

The result of this study showed that $33.7 \%$ of the models were one unit and $48.7 \%$ of the models were $2-4$ units and the remaining $17.5 \%$ of the models were more than five units, $8.7 \%$ of the models were without opposing arch. Alginate impression materials were used in $95 \%$ of the cases and only $5 \%$ of the cases elastomeric impression material were used. The finishing line was absent in $19.7 \%$ of the cases. Enough tooth reduction was done in $61.3 \%$ of the cases and $16.3 \%$ of the cases showed too much tooth reduction while $22.4 \%$ of the cases the tooth reduction was not enough. In order to avoid these errors continuous education courses and journal club are highly recommended.

Key Words: Dental models, dental impression techniques, dental communication.

\author{
Department of Conservative Dentistry \\ College of Dentistry, University of Mosul
}

$$
\begin{aligned}
& \text { الخلاصة }
\end{aligned}
$$

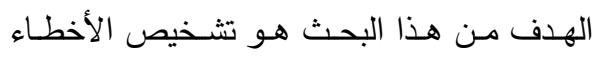

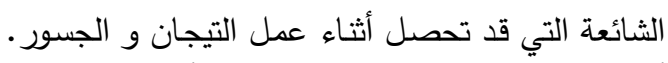

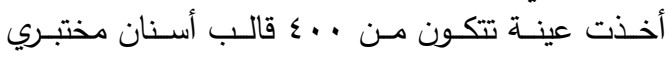

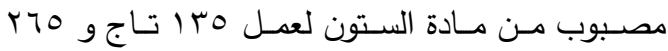

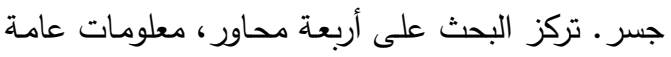

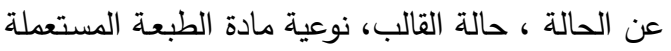

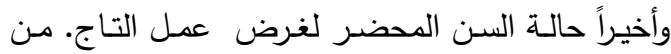

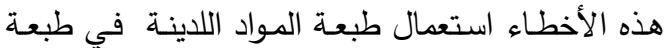

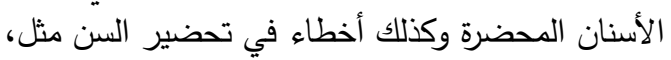

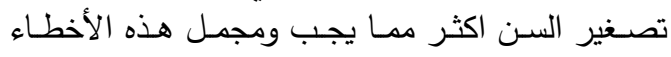

$$
\begin{aligned}
& \text { يؤدي إلى فثل العمل. }
\end{aligned}
$$

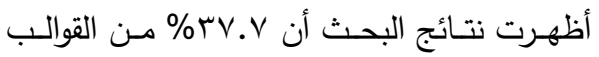

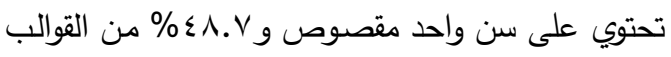

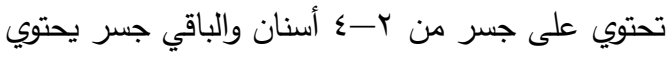

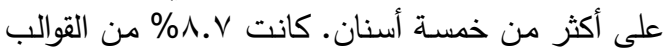

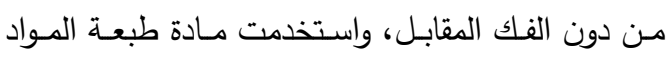

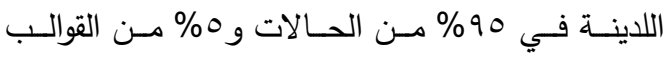

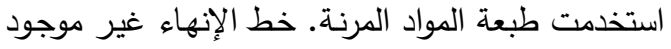

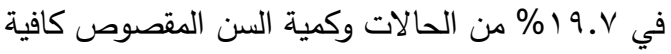

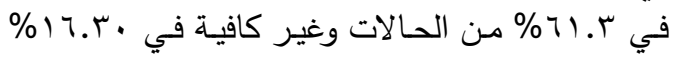

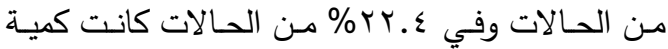

$$
\begin{aligned}
& \text { القص أكثر من المطلوب. ولأجل تجاوز هذه الأخطاء }
\end{aligned}
$$

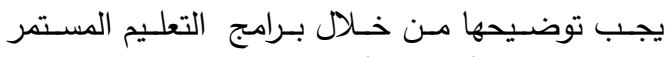

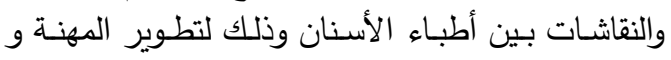

$$
\begin{aligned}
& \text { بالتالي خدمة المجمع بشكل افضل. }
\end{aligned}
$$

\section{INTRODUCTION}

The success of any bridge depends on many factors, clinical or laboratory features. Failure of one of these usually results in failure of the restoration. The prepa-ration of natural teeth for retention of crowns and bridges is based on two impor-tant principles. First, each tooth must be reduced so that its walls are not undercut, but a minimal convergence toward the oc-clusal or incisal must remain. Second, all the prepared teeth in a multiabutment pros-thesis should have parallel axes to produce a common path of insertion. Authorities on fixed prostheses agree with these princip-les, and several of them have proposed standards for the ideal amount of tooth taper. Tylman ${ }^{(1)}$ stated that the ideal taper degrees is 2 degrees on anterior teeth and $2-5$ degrees on posterior 
teeth, while Shill-ingburg et $a l .^{(2)}$ recommended a 6 degrees taper, Johnston et al. ${ }^{(3)}$ suggested 5-7 deg-rees, Kornfeld ${ }^{(4)}$ accepted a range that incl-udes all these figures.

A common error that occurs in the preparation of abutment teeth for crown and bridge is the inadequate removal of occlusal tooth structure to allow sufficient space for the restorative material. ${ }^{(5)}$

Location of gingival margin, the design and contour of the metal substructure are critical variables in design and esthetic of prosthetic restoration. ${ }^{(6)}$ The obstruction of embrasure spaces by metal will compromise the long term periodontal health of the restoration. ${ }^{(7)}$ The design of pontic region and metal contour may also contribute to hygiene complications, exposed metal margins and bulky prosthetic designs will compromise the esthetic and influence the adjacent soft tissue. ${ }^{(8)}$

The use of stock tray may result in dimensional changes and inaccuracies in the cast because of the variable thickness of the impression materials. ${ }^{(9-13)}$ Custom tray is advisable for procedures requiring the utmost accuracy. ${ }^{(2)}$

Alginate impression material (irreversible hydrocolloid) has been used primarily for opposing casts, study models, removable partial dentures, orthodontics and in limited extent in fixed partial prosthodontics, since the clinical use of alginate will not result in a high degree of accuracy in detail reproduction. $(11,14)$

Alginate impression materials are unstable unless poured immediately conversely elastomeric impression materials are more stable for several days prior to pouring and has better physical properties than alginate. ${ }^{(15,16)}$

The aim of this study was to evaluate the common errors that may occur during crown and bridge construction.

\section{MATERIAL AND METHOD}

In the present study, four hundred stone models were evaluated for the analysis. The stone models belong to 134 dentists that represent approximately $60 \%$ of private dental clinics in Mosul City. The evaluations of the stone models were done in private dental laboratory in Mosul City, the laboratory procedures were performed by one dental technician. The total number of units evaluated was 1141 for 265 bri-dges and 135 single crowns.

Four main parameters were evaluated for each stone model as shown in the Figure, general information about the case, the condition of the stone model, the type of impression material and the prepared abutment tooth.

The general information about the case includes, span of the bridge, type of the arch and location of the bridge. For the purposes of the analysis the types of bridges were divided into three groups. The first group included single tooth (crown), the second group included bridges of 2-4 units and the third group included bridges more than five units. The type of the arch was included whether maxillary or mandibular. Also the location of the bridge was determined which is either anterior or posterior.

The condition of the stone model was determined for the presence or absence of the opposing arch and by checking whether the stone model is full arch or sectional arch. The condition of the prepared abutment tooth was checked for presence of air bubbles, caries or any fracture in the prepared abutment tooth that was repaired.

The third parameter was checking the type of impression material, either elastomeric impression material or alginate impression material.

Analysis of the preparation included presence or absence of the finishing line, margin of finishing line which is divided into three groups: The first below the gingival margin, the second with the gingival margin and the third group above the gingival margin. Tooth reduction, which is also divided into three groups, the first group was enough reduction of the prepared tooth, the second group included too much reduction of the prepared tooth, while the third group determine teeth with less reduction. Then checking if undercuts are present on the abutment tooth, or if any sharp angles were present on the abutment tooth. Finally the smoothness of the preparation was checked. 


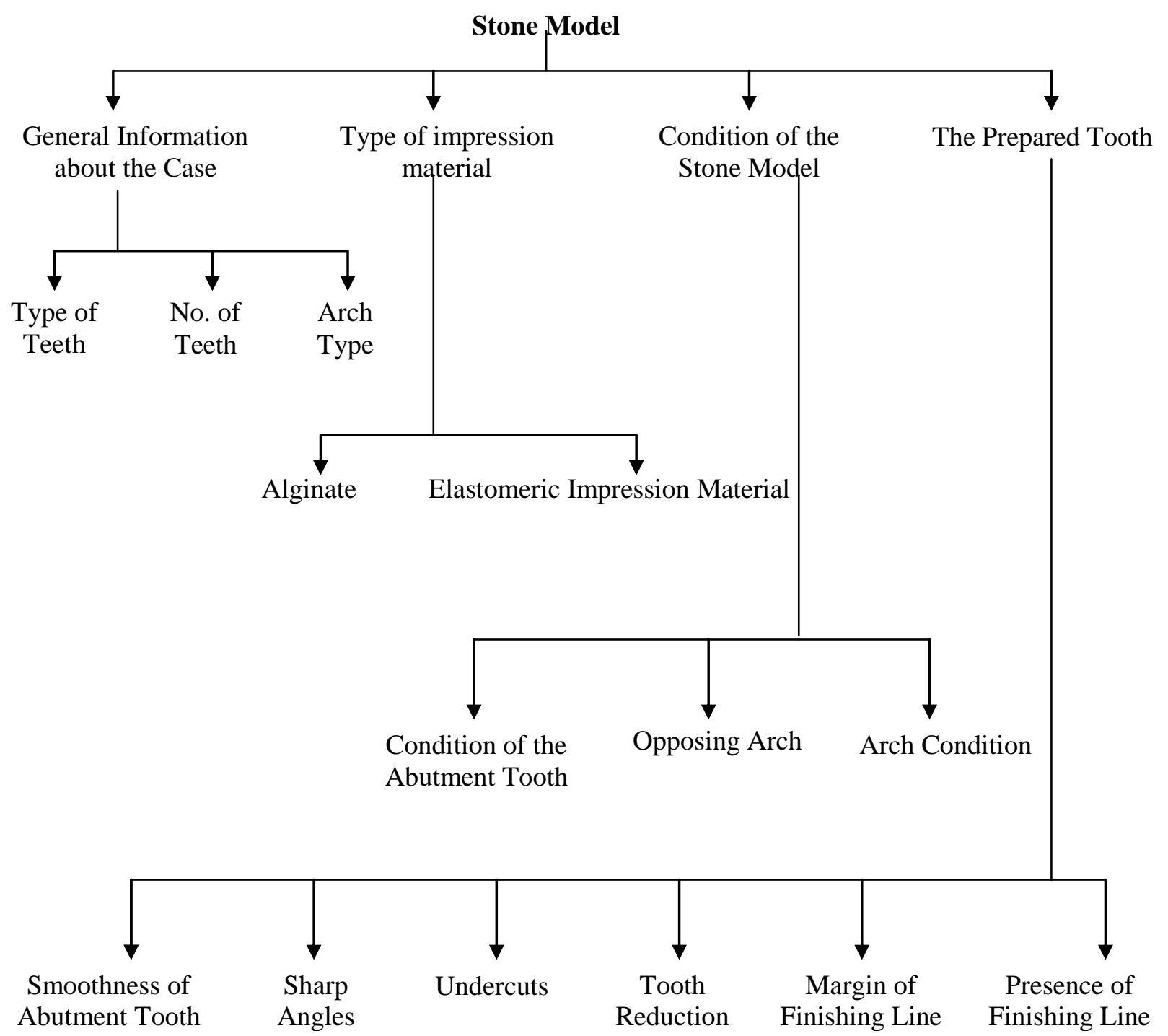

Figure: The main four parameters for evaluation of stone models

\section{RESULTS}

The results from the general information obtained were shown in Table (1). The span of the bridge, $33.7 \%$ of the models were one unit and $48.7 \%$ of the models were 2-4 units and the remaining $17.6 \%$ of the models were bridges more

Table (1): General information about the case

\begin{tabular}{|c|c|c|c|}
\hline \multirow{3}{*}{1} & \multirow{3}{*}{ Span of the Bridge } & Single Tooth & $337 \%$ \\
\hline & & Two-four Units & $48.7 \%$ \\
\hline & & Above Five & $17.6 \%$ \\
\hline \multirow{2}{*}{2} & \multirow{2}{*}{ Arch Type } & Maxillary & $63.7 \%$ \\
\hline & & Mandibular & $36.3 \%$ \\
\hline \multirow{2}{*}{3} & \multirow{2}{*}{ Location of the Bridge } & Anterior & $33.3 \%$ \\
\hline & & Posterior & $69.7 \%$ \\
\hline
\end{tabular}

Table (2) showed the results for the condition of the stone models the opposing arch were present in $91.3 \%$ of the cases than five units. The study showed that $63.7 \%$ of the stone models were for the maxillary arch and $36.3 \%$ were for the mandibular arch, $69.7 \%$ of the cases were bridges for posterior teeth and $33.3 \%$ of the cases were bridges for anterior teeth.

and absent in $8.7 \%$ of the cases. The stone models were full arch in $64.5 \%$ of the cases and $35.5 \%$ of the stone models were 
half arch. The condition of the abutment tooth showed that $81 \%$ of the stone models were without defects, $7.3 \%$ of the cases contain air bubbles, $8.1 \%$ of the stone models contain caries on the prepared abutment tooth and $3.6 \%$ of the stone models showed fracture on the abutment tooth that was repaired by zinc phosphate cement.

Alginate impression materials were used in $95 \%$ of the cases while $5 \%$ of the cases used elastomeric impression material.

Table (2): Condition of the stone model

\begin{tabular}{ccccc}
\hline \multirow{2}{*}{1} & \multirow{2}{*}{ Opposing Arch } & & Present & $91.3 \%$ \\
& & Absent & $8.7 \%$ \\
\hline \multirow{2}{*}{2} & \multirow{2}{*}{ Arch Condition } & & Full Arch & $64.5 \%$ \\
& & Sectional Arch & $35.5 \%$ \\
\hline \multirow{2}{*}{3} & \multirow{2}{*}{ Condition of the } & \multirow{2}{*}{ Without Defect } & $81 \%$ \\
& \multirow{2}{*}{ Abutment Tooth } & With & Presence of Air Bubbles & $7.3 \%$ \\
& & Defect & Presence of Caries & $8.1 \%$ \\
& & & Fracture of the Abutment Tooth & $3.6 \%$ \\
\hline
\end{tabular}

Table (3) showed the results of the prepared abutment teeth on the stone model, the finishing line were present in $80.3 \%$ of the cases while absent in $19.73 \%$ of the cases. The margin of the finishing line were below the gingival margin in 68 $\%$ of the cases and in $29.2 \%$ of the cases the finishing line was with the gingival margin and above the gingival margin in $2.8 \%$ of the cases. The study showed enough tooth reduction in $61.3 \%$ of the cases

Table (3): The prepared abutment tooth

\begin{tabular}{|c|c|c|c|}
\hline \multirow{2}{*}{1} & \multirow{2}{*}{ Presence of Finishing Line } & Present & $80.3 \%$ \\
\hline & & Absent & $19.7 \%$ \\
\hline \multirow{3}{*}{2} & \multirow{3}{*}{ Margin of Finishing Line } & Below Gingival Margin & $68 \%$ \\
\hline & & With Gingival Margin & $29.2 \%$ \\
\hline & & Above Gingival Margin & $2.8 \%$ \\
\hline \multirow{3}{*}{3} & \multirow{3}{*}{ Tooth Reduction } & Enough Reduction & $61.3 \%$ \\
\hline & & Too Much Reduction & $16.3 \%$ \\
\hline & & No Reduction & $22.4 \%$ \\
\hline \multirow{2}{*}{4} & \multirow{2}{*}{ Undercuts on the Abutment Tooth } & Present & $22.3 \%$ \\
\hline & & Absent & $77.7 \%$ \\
\hline \multirow{2}{*}{5} & \multirow{2}{*}{ Sharp Angles } & Present & $60.3 \%$ \\
\hline & & Absent & $39.7 \%$ \\
\hline \multirow{2}{*}{6} & \multirow{2}{*}{ Smoothness of Abutment } & Rough & $46.6 \%$ \\
\hline & & Smooth & $53.4 \%$ \\
\hline
\end{tabular}

The success of any fixed prosthodontic restoration depends on the case, dentist experience, and the communication and re-port of the dentist with the dental techni-cian. From the present study the common errors that occur are many, among these absence of the opposing arch in $8.7 \%$ of the stone models, sectional arch and too much reduction in $16.3 \%$ of the cases while the reduction was not enough in $22.4 \%$ of the cases. Undercuts were present on the abutment prepared teeth in $22.3 \%$ of the stone models, while $60.3 \%$ of the cases showed sharp angles on the prep-aration. Finally $46.6 \%$ of the examined stone models showed rough prepared abut-ment tooth and $53.4 \%$ of the cases showed smooth prepared abutment tooth

stone mo-dels in $35.5 \%$. Presence of air bubbles in $7.3 \%$, presence of caries on the prepared abutment teeth in $8.1 \%$, fracture of the abutment tooth on the stone model in $3.6 \%$ of the cases. These errors will lead to the sectional arch will not allow balance arti-culation and the bite is not always correct and unable to esthetically mirror the tooth in the other side of the arch. ${ }^{(17)}$ 
Presence of caries on the prepared abutment had a gre-ater chance of failing than caries free abut-ments. ${ }^{(18)}$ Also these faults will lead to poor marginal seal which is a critical fac-tor in success of dental restorations. ${ }^{(7,19)}$

Alginate impression materials were used in $95 \%$ of the cases. These wide uses of alginate are due to its low cost and ease of mixing and manipulation. The use of alginate as impression material in fixed prosthetic work is limited to study cast fabrication only because alginate does not transfer to gypsum much surface details as elastomeric impressions do, alginate has poor tear resistance and alginate is dimensionally unstable due to effects of syneresis, surface dehydration and imbibition. Therefore, the impression must be poured immediately. ${ }^{(16)}$ Elastomeric impressions must be used in fixed prosthetic works because they are more dimensionally stable than alginate, and their resistance to tearing is higher than alginate. Elastomeric impressions can be disinfected by most current antimicrobial solutions without adverse dimensional changes.

In the present study errors in the preparation of the abutment teeth were noted, absence of the finishing line in $19.7 \%$, too much reduction in $16.3 \%$, no reduction in $22.4 \%$, sharp angles in $60.3 \%$, and undercuts in $22.3 \%$ of the cases. Undercuts in individual preparations and nonparallelism of abutment result in an obstructed path of insertion. This is often dealt with at the dental laboratory by leaving margins open to compensate for bypassing the undercuts. In addition, excessive force must often be applied in seating such prosthesis. These compensation methods result in open mar-gins on the finished restoration, which may cause gingival irritation. The open margins are also subjected to cement was-hout which leads to marginal caries. ${ }^{(18,20,21)}$ To obtain an unobstructed path of insertion and avoid undercuts, preparations often are over tapered to the point that sacrifices the retention form, also it results in removal of too much tooth structure from the axial surfaces in the occlusal or incisal twothirds, which can place pulpal integrity in unnecessary danger. ${ }^{(22,23)}$ At the same time, too little tooth structure is removed cervically which causes a problem with contour, marginal fit, and esthetics of the finished restoration.

\section{CONCLUSIONS}

From this study many errors were noted in the construction of fixed prosthodontic restorations. In order to avoid these faults the following points must be noted:-

1- Elastomeric impression materials must be used, since these materials can pro-duce a high degree of accuracy in detail reproduction and the use of alginate must be limited to study cast and oppo-sing arch fabrication.

2- Stone models with faults, such as frac-ture, air bubbles and sectional arches, must be repeated and good cast with opposing arch must be sent to the den-tal laboratory.

3- Good preparation of the abutment teeth, chamfer finish line approximate-ly $0.3 \mathrm{~mm}$ deep are well suited for all metal crowns. Avoiding undercuts and nonparallelsim of abutment, over tape-ring of the abutment reduces retention and may place pulpal integrity in unne-cessary danger. At the same time too little tooth structure removal cervically will cause a problem with contour, ma-rginal fit and esthetic of the restoration. Line angles must be rounded.

4- Smooth tooth preparation appears to enhance the fit of restorations. Surface roughness generally increases retention with zinc phosphate cement, but its effect with adhesive cements has not been as definitely determined. A reasonably smooth tooth preparation is therefore recommended.

5- Continued education courses and jour-nal clubs are highly recommended in order to serve the community.

REFERENCES 
1- Tylman SD. Theory and Practice of Crown and Fixed Porsthodontics. $6^{\text {th }}$ ed. The CV Mosby Co. St Louis.1970; Pp: 228-290.

2- Shillingburg JrH, Hobo S, Whitsitt LD. Fundamentals of Fixed Prosthodontics. $\quad 2^{\text {nd }}$ ed. Quintessence Pub Co. Chicago. 1976.

3- Johnston JF, Phillips RW, Dykema RW. Modern Practice in Crown and Bridge Prosthodontics. $2^{\text {nd }}$ ed. WB Sau-nders Co. Philadelphia. 1965; p: 72.

4- Kornfeld K. Mouth Rehabilitation. $2^{\text {nd }}$ ed. The CV Mosby Co. St Louis. 1974.

5- Davidoff SR. Alternation of occlusal reduction of prepared abutment teeth subsequent to final impressions. J Pro-sthet Dent. 1985; 53:158-160.

6- Wilson PR. Effect of increasing cement space on cementation of artificial crow-ns. J Prosthet Dent. 1994; 71: 560-564.

7- Hung HS, Hung K. Marginal fit of por-celain-fused-metal and two types of ceramic crown. J Prosthet Dent. 1990; 63: 26-31.

8- White SN, Ingles S, Kipnis V. Influ-ence of marginal opening on microlea-kage of cemented artificial crowns. J Prosthet Dent. 1994; 71: 257-264.

9- Johnson GH, Craig RG. Accuracy of addition silicones as a function of tech-nique. J Prosthet Dent. 1986; 55: 197-203.

10- Eames WB, Sieweke JC, Wallace SW, Rogers LB. Elastomeric impression materials: Effect of bulk on accuracy. J Prosthet Dent. 1979; 41: 304-307.

11- Fusyama T, Kurosaki N, Node H, Nak-amura M. Laminated hydrocolloid imp-ression for indirect inlays. $J$ Prosthet Dent. 1982; 2: 171.

12- Phillips RW. Skinners Science of Den-tal Materials. $8^{\text {th }}$ ed. WB Saunders Co. Philadelphia.1982; $\mathrm{p}: 149$.

13- Rudd KD, Morrow RM, Eissmann Received: 19/6/2004
HF. Dental Laboratory Procedures: Remov-able Partial Dentures. The CV Mosby Co. St Louis. 1981; Pp: 58-68.

14- Appleby DC, Pameijer CH, Boffa J. Combined reversible/irreversible hydr-ocolloid impression system. $J$ Prosthet Dent. 1980; 44: 27.

15- Appley DC, Cohen SR, Racowsky LP, Minged EB. The combined reversible hydrocolloid/irreversible hydrocolloid impression system: Clinical applicat-ion. J Prosthet Dent. 1981; 44: 127.

16- Eames WB, Wallace SW, Suway NB. Accuracy and dimensional stability of elastomeric impression materials. J Pr-osthet Dent. 1979; 42: 159.

17- Trevor Burke FJ, Crisp RJ. A practice-based assessment of the handling of a fast-setting polyvinyl siloxane impress-ion material used with the dual-arch tray technique. Quintessence Int. 2001; 32: 805810.

18- Reuter JF, Brose MO. Failures in full crown retained dental bridges. Br Dent J. 1984; 157: 61-63.

19- Gelbard S, Aoskar Y, Zalkind M. Eff-ect of impression materials and techni-que on the marginal fit of metal cast-ings. $J$ Prosthet Dent. 1994; 71: 1-6.

20- Roberts DH. The failures of retainer in bridge prosthses. $\mathrm{Br}$ Dent J. 1970; 3: 117-124.

21- Coleman AJ, Rickerby HD, Antonoff LR. Macromolecular leakage beneath complete cast crowns. A 6-month in vitro investigation using microfluorimetry Quintessence Int. 2001; 32: 811-816.

22- Gold HO. Instrumentation for solving abutment parallelism problems in fixed prosthodontics. $J$ Prosthet Dent. 1985; 53: 172-179.

23- Goodacre CJ, Campagni WV, Aquilino SA. Tooth preparations for complete crown: An art from based scientific pri-nciples. $J$ Prosthet Dent. 2001; 85: 363-374.

Accepted for Publication: 25/9/2004 